\title{
Os Papéis dos Stakeholders na Implementação das Parcerias Público-Privadas no Estado da Bahia
}

SANDRO CABRAL

Universidade Federal da BaHia / Núcleo de Pós-Graduação em AdMinistração (NPGA-UFBA), SAlVAdor- BA, Brasil

antonio SÉrgio araújo fernandes

Universidade Federal da Bahia / Núcleo de Pós-Graduação em AdMinistração (NPGA-UFBA), SAlVAdor- BA, BraSiL

Daniel barroso de Carvalho Ribeiro

Universidade Federal do Piauí / Departamento de AdMinistração, PICOS- PI, Brasil

\begin{abstract}
Resumo
Este artigo analisa os papéis dos stakeholders na implementação de Parcerias Público-Privadas (PPP) no estado da Bahia. A pesquisa abarcou três experiências nas áreas de saúde, saneamento e esporte/cultura e avaliou todas as fases do ciclo de vida de cada PPP, da etapa inicial de enquadramento da proposta à execução contratual, passando pelas fases de financiamento e construção. Os principais resultados apontam que os diversos tipos de stakeholders (deliberantes, demandantes, controladores e financiadores) apresentam padrões de convergência e de divergência de interesses ao longo do ciclo de vida das PPP. De igual sorte, os achados da pesquisa revelam que os diversos stakeholders aparentam estar menos preparados para as etapas mais avançadas dos projetos. Tais resultados contribuem para os atuais debates sobre a aplicação da teoria de stakeholders no âmbito do setor público ao fornecer uma visão em perspectiva acerca dos padrões de atuação de grupos distintos de stakeholders em arranjos organizacionais inovadores como as PPP.
\end{abstract}

Palavras-chave: Parcerias Público-Privadas. Stakeholders. PPP em saneamento. PPP em saúde. PPP em estádios de futebol.

\section{Stakeholders' Roles in Implementing Public-Private Partnerships in the State of Bahia, Brazil}

\begin{abstract}
This article analyzes stakeholders' roles in implementing Public-Private Partnerships (PPPs) in the state of Bahia, Brazil. The research encompassed three experiences in the fields of health, sanitation, and sport/culture and it assessed all stages in the life cycle of each PPP, from the early stage of matching the proposal to contract execution, going through the funding and construction stages. The main findings show that the various stakeholder types (deliberative, claimant, controller, and funder) have converging and diverging stake patterns over the PPPs life cycle. In the same vein, survey findings reveal that the various stakeholders seem to be less prepared for the later project stages. Such results contribute to the current debates on applying the stakeholder theory to the public sector domain by providing a prospective view of the working patterns of various stakeholder groups in innovative organizational arrangements such as the PPPs.
\end{abstract}

Keywords: Public-Private Partnerships. Stakeholders. PPPs on sanitation. PPPs on health. PPPs on football stadiums.

\section{Los Roles de los Stakeholders en la Implementación de Asociaciones Público-Privadas en Estado de Bahia}

\section{Resumen}

Este artículo examina los roles de los stakeholders en la implementación de Asociaciones Público-Privadas (APP) en el estado de Bahia. La investigación abarcó tres experiencias en los campos de salud, saneamiento y deporte/cultura y evaluó todas las fases del ciclo de vida de cada APP, del paso inicial de marco de la propuesta hasta se contratar la ejecución, pasando por las etapas de financiamiento y construcción. Los principales resultados muestran que los diversos tipos de stakeholders (deliberativos, solicitantes, controladores y financiadores) tienen patrones de convergencia y divergencia de intereses a través del ciclo de vida de la APP. En la misma suerte, los resultados de la investigación muestran que los diversos stakeholders parecen ser menos preparados para las últimas etapas de los proyectos. Estos resultados contribuyen a los debates actuales sobre la aplicación de la teoría de stakeholders en el sector público para dar una idea de ver acerca de los patrones de acción de diferentes grupos de stakeholders en arreglos organizativos innovadores como las APP.

Palabras clave: Asociaciones Público-Privadas. Stakeholders. APP en saneamiento. APP en salud. APP en estadios de fútbol.

Artigo submetido em 10 de março de 2015 e aceito para publicação em 10 de novembro de 2015.

DOI: http://dx.doi.org/10.1590/1679-395147398 


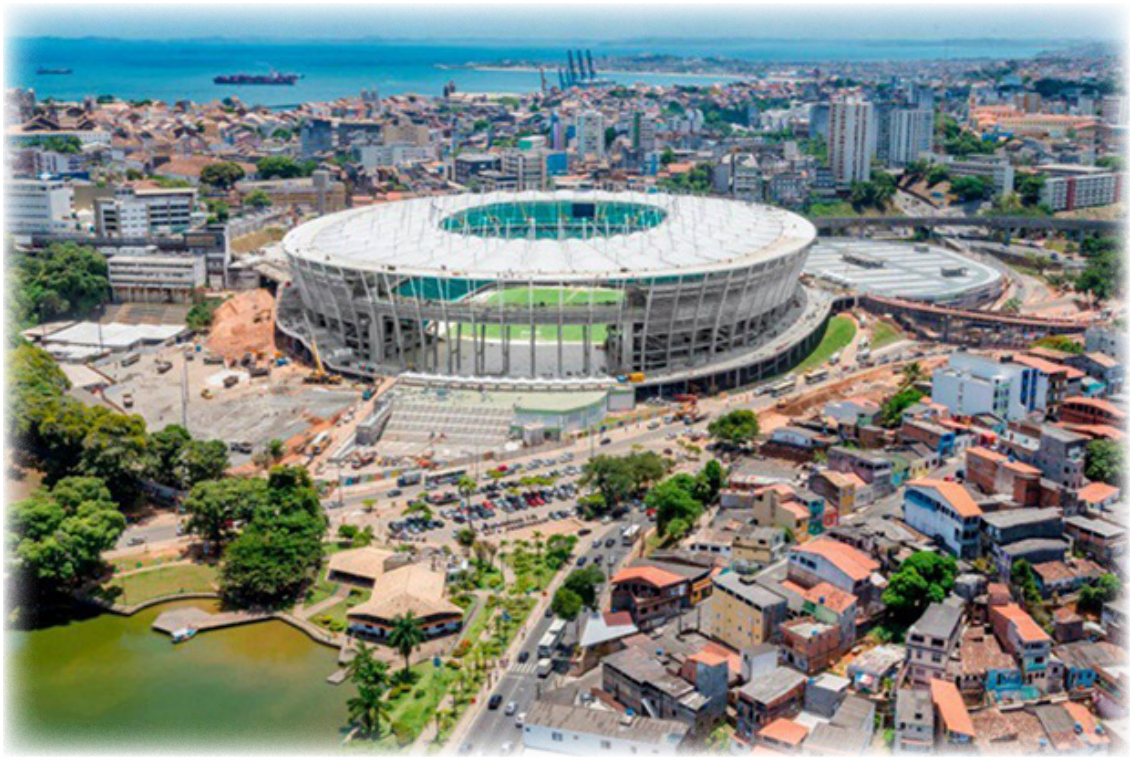

\section{INTRODUÇÃO}

Este artigo objetiva analisar os papéis dos stakeholders que influenciam a etapa de implementação das Parcerias PúblicoPrivadas (PPP) no estado da Bahia. Para tanto, as partes interessadas foram identificadas, suas atuações foram descritas e a importância que assumem no estado da Bahia durante a implementação das parcerias regidas pela Lei de PPP, Lei n. 11.079/04 (BRASIL, 2004), é indicada. Foram analisados os papéis dos stakeholders apontados nas fases próprias das PPP, revelando em cada momento o tipo de participação, tanto exclusiva como interdependente, e as interações existentes entre as diversas partes interessadas.

A escolha das PPP desenvolvidas pelos estados brasileiros justifica-se pelo crescente interesse sobre tal tipologia de contratação nesse nível federativo e pela necessidade de análise acerca do papel desempenhado pelas diversas partes interessadas que atuam e influenciam o desenvolvimento de PPP. O estado da Bahia como campo de pesquisa em PPP é relevante por apresentar projetos pioneiros nas áreas da saúde e de saneamento básico, além de ter experiências em diversas fases ao longo do ciclo de vida da PPP, desde a etapa inicial de enquadramento da proposta, passando pelas fases de financiamento e construção até chegar à fase de execução contratual. O exame da atuação dos stakeholders permite avaliar as circunstâncias que acrescentam aprendizados à gestão das parcerias analisadas. Para tanto, faz-se uso neste trabalho das teorias de stakeholders (FREEMAN, 1984) e de suas aplicações no setor público (GOMES, LIDDLE e GOMES, 2010a; 2010b). No âmbito deste trabalho serão abordados os seguintes projetos de PPP em execução no estado da Bahia ao longo do ano de 2013: PPP do Hospital do Subúrbio, PPP do Emissário Submarino Jaguaribe e PPP da Arena Fonte Nova. Afora estes, no momento de redação deste trabalho (setembro de 2015) encontravam-se em andamento os projetos de PPP do Novo Instituto Couto Maia, da PPP do Parque de Imagem e Diagnóstico (ambos na área de saúde) e a PPP do Metrô de Salvador.

Para atingir os objetivos propostos por este trabalho, valemo-nos de uma abordagem qualitativa mediante entrevistas em profundidade com catorze interlocutores, entre eles: o secretário de Trabalho, Emprego e Renda do estado da Bahia, o secretário da Fazenda do estado da Bahia, duas assessoras técnicas do setor da saúde, uma promotora de Justiça do estado, o presidente do consórcio hospitalar e de saneamento, da agência de fomento e de uma sociedade de economia mista, além de três gestores das áreas de investimentos em transporte e esporte e saneamento, além de dois gerentes de bancos financiadores dos projetos analisados. Além disso, foram analisados editais e atas de reuniões relativas aos projetos para completar os dados sobre as ações dos parceiros públicos e privados.

\footnotetext{
* Fonte da imagem: Arena Nova. Disponível em <http://www.copa2014.gov.br/pt-br/noticia/assentos-temporarios-da-fonte-nova-comecam-ser-instaladosno-dia-18-de-marco > Acesso em 14 mar. 2016.
} 
Este trabalho está dividido da seguinte maneira. Além desta introdução, mais cinco seções. A seção 2 trata da evolução das PPP, sobretudo a experiência brasileira. A seção 3 aborda a fundamentação teórica a respeito dos stakeholders e seus papéis. $\mathrm{Na} 4$ se apresentam os procedimentos de pesquisa, mostrando as categorias de análise e como essas foram desenvolvidas. Na seção 5 se apresentam os resultados do trabalho com a classificação dos papéis dos stakeholders das PPP estudadas no setor de saúde, saneamento e esporte e a seção 6 tece considerações finais à guisa de conclusão do texto.

\section{PARCERIAS PÚBLICO-PRIVADAS NA ÁREA DE INFRAESTRUTURA E O CASO BRASILEIRO}

A partir do fim do século XX, observa-se um processo de difusão internacional da ideia de desregulamentação setorial, em que, entre outras coisas, os países passaram a adotar mudanças na forma de financiamento e provisão de serviços de infraestrutura, fomentando a constituição de arranjos institucionais de parcerias entre os setores público e privado, tornando possível desenvolver concessões, terceirizações e privatizações. Fundamentalmente, tais processos se dão em resposta a limites orçamentários dos governos ao redor do mundo, além de crenças sobre uma suposta eficiência de formas organizacionais envolvendo atores privados na provisão de serviços públicos (CABRAL, LAZZARINI e AZEVEDO, 2013).

A experiência internacional mostra que as PPP podem representar uma alternativa para tornar viáveis empreendimentos de maneira eficiente e eficaz quando bem implementadas e com o arranjo institucional de regulação adequado (SAVAS, 2000). Para isso, faz-se necessário o conhecimento aprofundado dos instrumentos regulatórios e do ambiente institucional, bem como dos interesses convergentes e divergentes dos atores que comporão esse complexo arranjo.

Nesse diapasão, o Brasil criou um marco legal inicial da participação da atividade privada em obras e serviços públicos com a Lei de Concessões (Lei n. 8.987/1995), que regulamentou as privatizações nos setores de telecomunicação e energia elétrica, ocorridas ao longo da segunda metade da década de 1990 (PINHEIRO e GIAMBIAGI, 1997). A partir da primeira década do século XXI, inicia-se, pelo governo federal, a discussão sobre a adoção de um programa de PPP no Brasil que culminou com a criação da chamada "Lei das PPP" (Lei n. 11.079/2004), que estabelece os parâmetros para que o setor privado possa construir, operar e, inclusive, cobrar tarifas dos usuários dos serviços, porém, sem ser remunerado pelo setor público (CABRAL, 2006) ${ }^{1}$. À Lei n. 11.079/2004 buscou-se incorporar elementos considerados fatores críticos de sucesso, por outros países, destacando-se o enquadramento ao sistema legal existente, a preocupação com a disciplina fiscal, a adequada repartição de riscos entre os parceiros, as garantias ao parceiro privado e a necessidade de se instituir um órgão central para coordenar o processo de implementação das parcerias. Daí surgiram tipos de concessões que se diferenciaram da concessão tradicional no Brasil: a concessão administrativa e a administração patrocinada (BRITO e SILVEIRA, 2005; PASIN, 2005)².

Assim, a Lei das PPP submeteu-se a alguns aspectos existentes na legislação concernente à concessão e à licitação, mas também incorporou as inovações contidas nas normas de concessões patrocinadas e administrativas. Vários instrumentos normativos foram então criados para comportar as contratações de PPP também no âmbito estadual, como leis ordinárias e complementares, decretos, resoluções, portarias e instruções normativas. A pauta dos programas de PPP procura inserir tais figuras na agenda dos governos estaduais, mediante a execução de políticas contidas no Plano Plurianual (PPA), na Lei de Diretrizes Orçamentárias (LDO) e na Lei Orçamentária Anual (LOA) ${ }^{3}$, estando esses instrumentos alinhados à Constituição Federal de 1988 (ALVARENGA, 2005) e ao equilíbrio fiscal imposto pela Lei de Responsabilidade Fiscal, de 2001 (ARAGÃO, 2005) ${ }^{4}$. Com esse cenário, os primeiros projetos assumidos obtiveram forte apoio governamental, contando com empréstimos de até $80 \%$ do valor orçado pelo Banco Nacional de Desenvolvimento Econômico e Social (BNDES) nos estudos de viabilidade, por meio da estruturação embrionária dos marcos normativos que criaram condições para despertar o interesse privado pelos projetos.

\footnotetext{
${ }^{1}$ A Lei n. 11.079/2004 contrasta com a Lei de Licitações (Lei n. 8.666/1993), na qual o setor privado é apenas um fornecedor de produtos e serviços para a administração pública, sendo proibida a cobrança de tarifas e os contratos limitados a um prazo de cinco anos.

${ }^{2}$ A concessão administrativa nada mais é do que contrato de concessão de serviços públicos, com características peculiares, mas não substancialmente distinto da concessão comum, pois não há a cobrança de tarifa e o pagamento é incumbido exclusivamente ao Poder Público.

${ }^{3}$ Plano Plurianual, Lei de Diretrizes Orçamentárias e Lei Orçamentária Anual são mecanismos do planejamento governamental instituídos pela CF/1988 e normatizado pelo Decreto n. 2.829 e o Ministério do Planejamento e Orçamento emite a Portaria n. 117 de 12/11/1998.

${ }^{4}$ Lei de Responsabilidade Fiscal n. 101, de 4 de maio de 2000.
} 


\section{A IMPORTÂNCIA DOS STAKEHOLDERS EM PROCESSOS DE PARCERIAS PÚBLICO-PRIVADAS}

Na abordagem conceitual relacionada aos stakeholders há um argumento de que a organização tem muitas relações com grupos internos e externos e que estas podem fornecer apoio a determinados objetivos comuns, considerando o equilíbrio dos seus interesses (CLARKSON, 1995; EVAN e FREEMAN, 1993; FREEMAN, 1984; JONES e WICKS, 1999). Os estudos sobre os interessados em lucros e na ética, em grande parte conduzidos segundo análise de organizações privadas, têm sido também aplicados à compreensão de organizações públicas (HILLMAN e KEIM, 2010; HASNAS, 1998).

Mason e Mitroff (1981) ajudaram a introduzir a análise das partes interessadas para a prática de negócios. Em sua definição, stakeholders são todos aqueles requerentes, dentro e fora da empresa, que têm interesse no problema em questão e na sua solução, sendo as entidades concretas que afetam e são afetados por uma política. Uma grande contribuição à teoria de stakeholders pode ser encontrada na obra de Donaldson e Preston (1995), em que descrevem uma organização como uma constelação de interesses cooperativos e competitivos que têm valor intrínseco. Os autores afirmam que a descrição da organização é fundamental para ajudar as pessoas a examinar as práticas normativas para instituir as partes interessadas que merecem atenção e as práticas de gestão ao recomendar estruturas e atitudes existentes no sistema de interesse das empresas.

Por seu turno, processos de PPP, assim como outras políticas públicas, requerem um espaço de gestão ou governança partiIhado, onde os stakeholders ocupam lugares importantes. Eles serão responsáveis por desempenhar inúmeros papéis na gestão da PPP que vão do controle à discussão do risco contratual, passando pelo monitoramento de desempenho. Nessa seara, a identificação dos stakeholders, no âmbito de políticas públicas, e de seus principais papéis é fundamental. Um exemplo é a concepção de usuários e operadores de objetos de políticas públicas. Nesse caso, quando comparado aos cidadãos-usuários de bens ou serviços públicos, tem-se a nítida separação entre os papéis dos beneficiários, assumidos pelos cidadãos, e os papéis de operadores, assumidos predominantemente pelo Estado (BRYSON, 1995; ALEXANDER, 2005). No mesmo diapasão, o estudo de Gomes, Liddle e Gomes (2010b) desenvolve análise para a identificação das partes interessadas em municípios brasileiros. Os autores propõem três categorias: atores com poder de voto, atores com poder econômico e atores com poder político. Outra metodologia para a identificação das partes interessadas, também para o setor público, foi proposta por Winstanley, Sorabji e Dawson (1995) e baseada em duas dimensões. A primeira refere-se ao poder de definir os critérios pelos quais os serviços devem ser prestados, por meio do estabelecimento de objetivos de serviços públicos, do escopo de seu provimento e dos padrões de desempenho para a adequada avaliação dos resultados finais. A outra importante dimensão trata do poder de definir os procedimentos para prestação de serviços públicos das partes interessadas responsáveis pela entrega dos serviços em si e os capazes de alterar a forma como os serviços são prestados.

Por sua vez, Savage, Taylor, Rotarius et al. (1997) apresentam um modelo alternativo para classificar os interessados com base em duas dimensões: a capacidade de cooperação e o potencial para ameaçar a organização. Nesse esquema, os interessados são categorizados como: stakeholders de apoio - os que oferecem baixa ameaça potencial à organização e alto potencial cooperativo - e os interessados marginais - não sendo estes nem altamente ameaçadores nem especialmente cooperativos. De igual sorte, os stakeholders não apoiadores representam uma grande ameaça potencial e um baixo potencial de cooperação; e, por último, há os interessados em benefícios, com o comportamento de alto potencial para ameaçar, bem como para cooperar... Ainda no quesito classificação de stakeholders, Bowker e Leigh Star (1999) afirmam que os sistemas de classificação devem apresentar princípios consistentes, categorias mutuamente exclusivas e com a completude inatingível. Ela fixa que uma pessoa pode desempenhar vários papéis, e é impossível ter certeza de que novos papéis não irão surgir, logo qualquer classificação das partes interessadas deve ser provisória, na melhor das hipóteses. Outro avanço é adicionado por Avison e Wood-Harper (1998) ao formular a Visão Múltipla de stakeholders. Considerada uma abordagem respeitada, a concepção baseada em pontos de vista múltiplos dos intervenientes em um sistema apresenta ferramentas e técnicas apropriadas à situação-problema. A visão múltipla foi além de várias maneiras, incluindo um estudo sistêmico das partes interessadas em sua análise organizacional e uso da etnografia na análise sociotécnica.

No âmbito deste trabalho, a identificação dos stakeholders se vale da abordagem proposta por Sharp, Galal e Finkelstein (1999), Gomes, Liddle e Gomes (2010b) e Savage, Taylor, Rotarius et al. (1997), em que diversos atores são identificados com base em interações sucessivas com o campo, tendo em mente o potencial de colaboração e alinhamento em relação aos objetivos formulados pelo governo promotor da PPP. A classificação adotada, conforme pode ser observado adiante, emergiu com o avanço dos trabalhos de campo. 


\section{PROCEDIMENTOS DE PESQUISA}

Foi adotado aqui o método de narrativa analítica que propõe aproximar-se da realidade social em suas características processuais e vinculadas à ação, o que possibilita organizar o fluxo de eventos observados em função de um sentido global atribuído ao fenômeno em estudo, prestando-se a apreender a realidade social como processo. O método é construído a partir de evidências factuais e históricas com o objetivo de explicar as ações relevantes e atividades investigadas, com base em um modelo teórico que possa compreender as principais características dos episódios, ou as diferenças significativas existentes entre estes (BARZELAY e CORTAZAR-VELARDE, 2004; FERNANDES, 2010; FERNANDES e ARAÚJO, 2015). Desse modo, o método das narrativas se baseia em eventos e não em variáveis - centra-se na explicação contextualizada e não abstraída das particularidades do objeto de estudo. A explicação a respeito do fenômeno pesquisado é obtida da construção de uma narrativa lógica, de onde as relações entre eventos e decisões são explicadas com base no fluxo de ações referido ao contexto em que estes ocorreram.

O resultado da aplicação do método narrativo é o relato, definido como "uma forma de representar uma experiência que conecta os acontecimentos em função do efeito que exercem sobre a experiência global" (BARZELAY e CORTAZAR-VELARDE, 2004, p. 23-24). O relato é composto por dois elementos básicos: os "eventos" e a "trama" (BARZELAY e CORTAZAR-VELARDE, 2004, p. 25). Os eventos são "delineados, descritos e analisados em função do resultado ou 'estado final' ao qual influenciaram os acontecimentos" ou "de uma trajetória que se considere merecedora de análise" (FERNANDES e ARAÚJO, 2015, p. 297).

No âmbito deste trabalho são discutidos os papéis dos stakeholders em três PPP no Estado da Bahia: a PPP do Hospital do Subúrbio, a PPP do Emissário Submarino Jaguaribe e a PPP da Arena Fonte Nova. A escolha dessas iniciativas deve-se ao fato de os projetos estarem em fase de operação no momento de conclusão da pesquisa (meados de 2013), permitindo assim a avaliação da influência dos stakeholders ao longo de todo o ciclo de vida da PPP, da definição das necessidades à execução contratual. Foi usada a técnica snowball sampling, em que os participantes são identificados pelo reconhecimento de atores inicialmente contatados, ainda que pertencentes a categorias profissionais distintas (PATTON, 2005). Foram feitas catorze entrevistas semiestruturadas com dirigentes das organizações envolvidas nos três projetos de PPP analisados neste trabaIho. Além disso, foi feita uma análise documental. Nesse caso, a leitura dos documentos (atas de reunião, editais, notas de imprensa, comunicados oficiais) foi guiada pela busca de informações relativas à identificação dos stakeholders relevantes, bem como sua respectiva influência sobre cada PPP analisada. Os pontos mais relevantes foram registrados à parte. A combinação das entrevistas com os documentos permitiu a elaboração da narrativa analítica visando a discutir a dimensão dos stakeholders no contexto das PPP do estado da Bahia a partir da análise da atuação e relevância desses atores, bem como das divergências e do equilíbrio de interesses influenciados no andamento dos projetos.

O Quadro 1 ilustra o modelo de análise adotado nos procedimentos metodológicos.

\section{Quadro 1}

\section{Esquema de análise dos projetos de Parcerias Público-Privadas no estado da Bahia}

\begin{tabular}{|c|c|c|c|}
\hline Dimensão & Contexto & Componentes & Indicadores \\
\hline \multirow{9}{*}{$\begin{array}{l}\text { Papéis dos } \\
\text { stakeholders }\end{array}$} & \multirow{9}{*}{$\begin{array}{l}\text { Projetos de } \\
\text { Parcerias } \\
\text { Público- } \\
\text { Privadas no } \\
\text { estado da } \\
\text { Bahia }\end{array}$} & \multirow{3}{*}{$\begin{array}{l}\text { Atuação e } \\
\text { relevância dos } \\
\text { stakeholders }\end{array}$} & $\begin{array}{l}\text { Descrição da participação dos stakeholders em cada fase } \\
\text { da PPP }\end{array}$ \\
\hline & & & Relevância primária e secundária dos stakeholders \\
\hline & & & $\begin{array}{l}\text { Interfaces entre os stakeholders durante as fases do } \\
\text { projeto }\end{array}$ \\
\hline & & \multirow{6}{*}{$\begin{array}{l}\text { Divergência e } \\
\text { equilíbrio de } \\
\text { interesses }\end{array}$} & Impasses entre os participantes dos projetos \\
\hline & & & Interdependência de ações dos stakeholders \\
\hline & & & $\begin{array}{l}\text { Funções opostas ou convergentes em uma mesma fase } \\
\text { do projeto }\end{array}$ \\
\hline & & & Mecanismos para o balanceamento de interesses \\
\hline & & & Ajustes dos interesses \\
\hline & & & Beneficiados nas decisões \\
\hline
\end{tabular}

Fonte: Elaborado pelos autores. 
Os indicadores adotados emergiram de contínuas interações entre referenciais teóricos e dados empíricos, na linha do defendido por Strauss e Corbin (1990). Como forma de conferir um sentido lógico que demonstrasse a evolução das PPP analisadas ao longo de seu ciclo de vida, as informações coletadas em entrevistas e em análise documental foram organizadas de acordo com os componentes de cada fase (Quadro 2). De maneira esquemática, o exame da documentação, as interações com os entrevistados e o confronto com a literatura permitiram delimitar as fases e os processos de PPP na Bahia, e possivelmente para o Brasil, nas seguintes etapas: enquadramento das propostas, licitação, financiamento, construção, gestão do contrato e controle da gestão da PPP. Naturalmente, os diversos stakeholders apresentam padrões distintos de comportamento ao longo de cada fase.

\section{Quadro 2}

Fases e processos das Parcerias Público-Privadas na Bahia

\begin{tabular}{|c|c|}
\hline Fases & Processos \\
\hline \multirow{7}{*}{ Enquadramento das propostas } & Elaboração do Projeto Preliminar \\
\hline & Encaminhamento ao Conselho Gestor da Parceria Público-Privada (CGP) \\
\hline & Autorização para a realização de Estudo Técnico \\
\hline & Procedimento de Manifestação de Interesse \\
\hline & Consulta e Audiência Pública \\
\hline & Pareceres dos Membros do CGP \\
\hline & Enquadramento no Plano Estadual de PPP \\
\hline \multirow{2}{*}{ Licitação da PPP } & Processo Licitatório \\
\hline & Assinatura do contrato \\
\hline \multirow{3}{*}{ Financiamento da obra } & Negociação do empréstimo \\
\hline & Análise da proposta de financiamento \\
\hline & Contratação do financiamento \\
\hline \multirow{2}{*}{ Construção } & Construção da infraestrutura \\
\hline & Compra de equipamentos \\
\hline \multirow{3}{*}{ Gestão do contrato } & Contratação de pessoal e compra de insumos \\
\hline & Inauguração e prestação de serviços \\
\hline & Recebimento da contraprestação \\
\hline \multirow{2}{*}{ Controle da gestão } & Auditoria do poder concedente \\
\hline & Parecer do verificador independente \\
\hline
\end{tabular}

Fonte: Elaborado pelos autores.

O Quadro 3 ilustra os projetos de PPP no estado da Bahia. Conforme pode ser apreendido, os três exemplos focalizados neste trabalho percorreram todas as fases, justificando, assim, as escolhas feitas. 


\section{Quadro 3}

Projetos e fases das Parcerias Público-Privadas do estado da Bahia (2004-2013)

\begin{tabular}{|c|l|l|l|l|}
\hline Projetos/Fases & Enquadramento & Licitação & $\begin{array}{c}\text { Financiamento e } \\
\text { Construção }\end{array}$ & Gestão e Controle \\
\hline $\begin{array}{c}\text { Pospital do Subúrbio * } \\
\text { Imagem }\end{array}$ & & & & \\
\hline $\begin{array}{c}\text { Instituto Couto Maia } \\
\text { Emissário Submarino } \\
\text { Jaguaribe* }\end{array}$ & & & & \\
\hline Arena Fonte Nova* & & & & \\
\hline $\begin{array}{c}\text { Metrô Salvador-Lauro de } \\
\text { Freitas }\end{array}$ & & & & \\
\hline $\begin{array}{c}\text { Plataforma Logística do } \\
\text { São Francisco }\end{array}$ & & & & \\
\hline
\end{tabular}

Fonte: Elaborado pelos autores

* Projetos focalizados neste trabalho.

Nas próximas seções são discutidas a relevância dos atores, suas divergências e o equilíbrio de interesses no decorrer das fases particulares às PPP. Entende-se como divergências aspectos que explicitem posições antagônicas entre os stakeholders, não raro conflituosas, e que minam o avanço das PPP. Por outro lado, aspectos convergentes são aqueles que ressaltam alinhamento de interesses e preferencias entre as partes interessadas e que acabam por contribuir para que as PPP avancem e possam efetivar sua contribuição à sociedade. A Figura 1 ilustra os possíveis papéis a ser desempenhados pelos stakeholders sobre as PPP em execução.

\section{Figura 1}

\section{Papéis a ser desempenhados pelos stakeholders sobre as Parcerias Público-Privadas em execução}

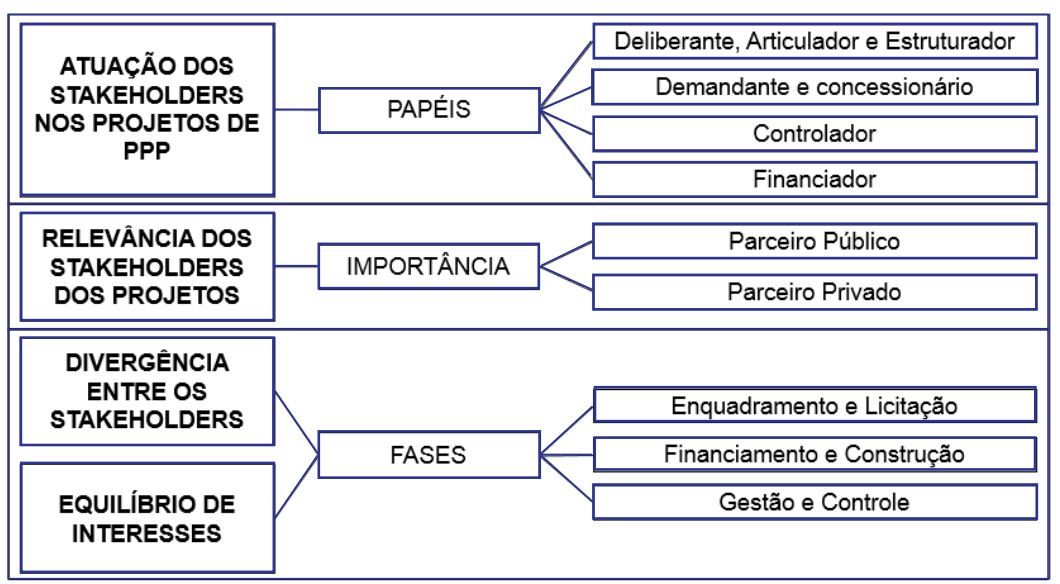

Fonte: Elaborada pelos autores. 


\section{RESULTADOS}

Neste estudo foram identificados os seguintes stakeholders: i) deliberantes, articuladores e estruturadores; ii) demandantes e concessionários; iii) controladores; e iv) financiadores. Cada um desses atores tem maior ou menor grau de influência, a depender da fase do projeto, ou do tipo do projeto em si. Esta seção discute tais aspectos tendo como referência os papéis desempenhados por cada ator ou grupo de atores em cada um dos três projetos analisados.

\section{Stakeholders deliberantes, articuladores e estruturadores}

Os stakeholders classificados como deliberantes, articuladores e estruturadores potencializam a capacidade do estado de formar uma carteira de projetos estruturantes sob o modelo de PPP. Por meio de entrevistas e da análise de documentos relevantes foi possível verificar que ao aproximar interesses comuns do governador, secretarias, consórcios, financiadores e controladores, esses atores propagam suas participações sobre quase todos os projetos e fases, e, por essa razão, acumulam a expertise sobre a consecução dos processos no andamento dos trabalhos. Nessa linha, um dos principais atores identificados, a Unidade de Parceria Público-Privada (UPPP) vinculada à Secretaria da Fazenda do Estado da Bahia, figura em várias frentes, se apresentando como um órgão articulador, que apoia toda a preparação dos projetos de PPP no estado da Bahia, desde a origem da demanda inicial de uma secretaria específica que questiona a probabilidade da inserção de um dado projeto na carteira de investimento em PPP no estado.

A unidade em tela encarrega-se da análise do enquadramento das propostas acerca dos custos, previsão, interesses, objetivos, além de instruir a estruturação da modelagem econômico-financeira que poderá ocorrer mediante um Procedimento de Manifestação de Interesse (PMI), ou por meio de um processo licitatório para a contratação de consultoria, ou com a articulação para a elaboração de estudo por intermédio de stakeholders estruturadores dos projetos associados a algum organismo multilateral. Entre os principais parceiros nessa empreitada figuram o International Finance Corporation (IFC), a Estruturadora Brasileira de Projetos (EBP), pertencente ao BNDES, e a Corporação Andina de Fomento (CAF) ligada ao Banco Interamericano de Desenvolvimento (BID). No intuito de obter apoio específico na parte inicial dos projetos, os dados levantados revelam o recurso a parceiros privados, como as consultorias KPMG e Pezco. Como ocorreu nos projetos da área de saúde, saneamento e esporte, assim como as fundações de apoio ligadas a universidades, como Fundação Coordenação de Projetos, Pesquisas e Estudos Tecnológicos (Coppetec) da Universidade Federal do Rio de Janeiro (UFRJ) e a Fundação Instituto de Administração (FIA), ligada a professores da Universidade de São Paulo (USP). Conforme verificado durante as entrevistas, tal articulação, além de qualificar melhor os aspectos técnicos das propostas, contribui para aumentar a legitimidade do programa de PPP e mitigar eventuais pressões contrárias provenientes de outros stakeholders. Ou seja, as evidências sugerem que o estabelecimento de coalizões de stakeholders, lideradas por um órgão central; nesse caso a UPPP configura-se como aspecto importante para que as PPP possam avançar ao longo da cadeia e, talvez mais importante, proporcionar a internalização do aprendizado necessário para futuros projetos estruturantes, a exemplo dos legados gerenciais observados a partir da Copa do Mundo Fifa 2014 (TEIXEIRA e CABRAL, 2014).

\section{Stakeholders demandantes e concessionários das Parcerias Público-Privadas}

Em que pese a atuação dos deliberantes, articuladores e estruturadores, em consonância com a literatura (FISCHBACHER e BEAUMONT, 2003; FORRER, KEE, NEWCOMER et al., 2010) é possível verificar por meio da pesquisa de campo que os demandantes e os concessionários são fundamentais para a concretização das PPP. Nessa seara, situam-se as atuações da sociedade de economia mista, das secretarias e consórcios dos setores da saúde, transporte, esporte e saneamento. Nesse caso, além das secretarias de estado (Sesab-Secretaria de Saúde, PPP do Hospital do Subúrbio e Setre-Secretaria do Trabalho Emprego e Renda, PPP da Arena Fonte Nova) e sociedades de economia mista (Empresa Baiana de Águas e Saneamento - Embasa, PPP do Emissário Submarino), figuram também como stakeholders relevantes, os concessionários comtemplados: a Prodal Saúde, a Fonte Nova Participações (FNP) e Foz do Brasil, bem como os consórcios concorrentes nas licitações. Em razão da heterogeneidade de cada arranjo, cada PPP será discutida separadamente. 


\section{Parcerias Público-Privadas na área da saúde - hospital do subúrbio}

As evidências empíricas coletadas revelam que, no segmento da saúde, a Sesab caracteriza-se, principalmente, pelo papel de demandante. No entanto, atua nos projetos de PPP no processo de deliberação e em outras fases mais avançadas, com outros atores em situações específicas de cada caso. Uma das entrevistadas, à época ocupando função de assessoria no gabinete para projetos especiais da Sesab, ao recuperar os fatos em torno do projeto do Hospital do Subúrbio, a primeira PPP da área da saúde no Brasil, revelou a preocupação sobre o julgamento da sociedade sobre a iniciativa da contratação de uma PPP, até então muito confundida com a privatização. Em razão de tais preocupações, cuidados foram tomados na estruturação da PPP, sobretudo no que diz respeito à forma de sua fiscalização. Com o formato da parceria, regida pela Lei n. 11.079/2004 (BRASIL, 2004), de acordo com o edital e o contrato assinado entre as partes, a empresa vencedora do certame deveria executar os serviços à sua maneira, sem a interferência do estado, porém, sob forte supervisão do órgão demandante por meio de um sistema de indicadores de desempenho definidos em contrato e auditados por verificador independente. Segundo a assessora, na PPP em tela não se diz ao consórcio vencedor responsável pela operação do equipamento, por exemplo, o tratamento ou o medicamento que deve ser administrado aos pacientes, porém, exige-se o resultado esperado observável nos indicadores de desempenho aferidos. Acrescentando às experiências de design das PPP, para esse contrato em especial, o estado assumiu as funções de planejar, desenhar, construir e controlar o empreendimento. Diferentemente dos demais projetos, o estado integralizou o investimento em instalações prediais, cabendo ao parceiro privado a aquisição dos equipamentos e a operação clínica da unidade.

O exame dos documentos e dos depoimentos de entrevistados revela que o organismo demandante apresentou papel-chave no que respeita à articulação técnica e política para tornar viável a PPP do Hospital do Subúrbio. Processualmente, depois de esclarecido o formato básico do serviço, a Secretaria de Saúde da Bahia levou o projeto do Hospital do Subúrbio ao Conselho Gestor de Parcerias Público-Privadas (CGP) para a deliberação e conformação da demanda da Sesab na agenda existente na carteira de projetos que concorrem aos recursos limitados que o governo tem para a contratação de PPP, na época, definidos em 3\% da Receita Corrente Líquida (RCL) do estado. Atualmente, esse percentual se elevou para 5\%. Com base nisso, o Conselho Gestor reúne seus membros, Secretaria da Fazenda (Sefaz), Secretaria de Planejamento, Secretaria Casa Civil, Procuradoria-Geral do Estado (PGE), Secretaria de Administração, a Secretaria de Infraestrutura, a Secretaria de Indústria e Comércio e outra secretaria finalística interessada, para ordenar os projetos, conforme a prioridade, que obviamente considera, além dos projetos presentes, outros que ainda não estão no portfólio de PPP e que o estado pretende incluir. Nesse sentido, ao impor sua agenda perante os demais atores, a Sesab mostrou-se um stakeholder capaz de direcionar o processo de escolha das prioridades do estado. Sendo assim, observa-se aí um indício da teoria de gestão dos stakeholders no momento em que o estado estabelece prioridades (MITCHELL, ANGLE e WOOD, 1997; BOESSO e KUMAR, 2007).

A participação da Sesab participa é verificada em todas as fases do ciclo de vida da PPP, indo além da deliberação, indo da concepção da ideia do projeto ao pelo controle da gestão do hospital, passando pela arguição perante o Conselho Gestor de PPP (CGP). O acúmulo de papéis de um stakeholder-chave aparenta prescindir de competência técnicas e políticas, que, uma vez presentes, podem explicar porque determinados projetos de PPP avançam ao passo que outros são abortados ou desenvolvidos de forma mais lenta.

\section{Parcerias Público-Privadas da Arena Fonte Nova}

Na área de esportes, o estado da Bahia abriga o projeto da Arena Fonte Nova sobre o qual a Secretaria do Trabalho, Renda e Esporte (Setre) tem a liderança contratual e o papel de demandante. Em entrevista com o secretário dessa pasta anotou-se que a PPP do estádio foi elaborada por muitas mãos, com as participações decisivas da Procuradoria-Geral do Estado (PGE), do secretário executivo da Unidade de PPP, vinculada à Secretaria da Fazenda, com a Desenbahia (Agência de Fomento do Estado da Bahia S.A.), o Banco do Nordeste (BNB) e BNDES, que analisaram e concederam os empréstimos para o projeto.

O processo de articulação da Sertre junto a outros stakeholders iniciou-se em 2008, pela análise das propostas no âmbito do Procedimento de Manifestação de Interesse (PMI) para a Arena Fonte Nova. Em meio à diversidade de propostas apresentadas, a Sertre, com o apoio da FIA, optou por um projeto que primava pela demolição do estádio antigo e a construção de um novo equipamento, em que pese a existência de propostas com menores custos e tecnicamente aderentes ao padrão Fifa. Tendo sido escolhida a PPP como modalidade de provisão, a modelagem institucional contou com o apoio da consultoria 
KPMG e revisão da consultoria Pezco Microanalysis, o que contribuiu para atenuar, mas não eliminar, as pressões contrárias de stakeholders ocupando o papel de agentes de controle (notadamente o Tribunal de Contas do Estado e o Ministério Público da Bahia).

A Fonte Nova Participações (FNP), consórcio formado pelos grupos Odebrecht e OAS, foi a parceira privada vencedora da licitação, tendo sido responsável pela demolição, reconstrução e operação da nova arena de esportes e multiuso. Com a classe de concessionário, a FNP é ator que desenvolve o projeto para atender às várias exigências do Estado e da Fifa, no caso para poder sediar jogos do mundial de futebol realizado em 2014. A habilidade para construção nos prazos estipulados e segundo os parâmetros de custos correspondentes a valores de mercado (CABRAL e SILVA JR., 2014) proporcionou a legitimidade do arranjo e seu relativo sucesso.

\section{Parcerias Público-Privadas do Emissário Submarino}

A Empresa Baiana de Água e Saneamento (Embasa) é o demandante principal do projeto do Emissário Submarino, que foi a primeira PPP do estado da Bahia a ser contratada no fim de 2006. Com independência administrativa e financeira, a sociedade de economia mista planejou e conduziu o processo de contratação da obra, em regime de urgência, com a inexigibilidade da licitação, algo bastante contestado à época. A PPP do Emissário foi concebida para beneficiar, na primeira fase, mais de 1,9 milhão de habitantes, dando destinação adequada aos esgotos domésticos coletados na Zona Norte de Salvador e no município de Lauro de Freitas (BARBOSA, CABRAL e SOUZA, 2009). O empreendimento consumiu R\$ 259 milhões, sendo R\$ 174 milhões financiados pela Caixa Econômica Federal (CEF) e R\$ 85 milhões aplicados pela Foz do Brasil, empresa do grupo Odebrecht que operará o sistema por quinze anos.

O exame das fontes qualitativas revela que a Embasa e a concessionária vencedora foram stakeholders importantes para viabilização da PPP. Com efeito, um dos executivos entrevistados atesta que a atuação do consórcio vencedor se iniciou a partir do lançamento do edital para a contratação da PPP do Emissário. O executivo recupera que para o consórcio tomar o empréstimo teve de criar duas "Sociedades de Propósito Específico" (SPE), como forma de atender às exigências da CEF para concessão do financiamento da construção. A primeira SPE, denominada Jaguaribe Construções, tomou o financiamento para a obra, construiu o emissário submarino. Já a outra sociedade, chamada de Jaguaribe S/A, se envolveu especificamente para a operação do sistema, cumprindo, assim, a regra da estanqueidade para a contabilização das duas empresas. A segunda sociedade foi transformada na Foz do Brasil, fundada no início de 2009, depois da holding do Grupo Odebrecht decidir investir na criação de uma concessionária diretamente voltada para o setor de saneamento. A nova sociedade passou a ser acionista da SPE junto à CNO (Construtora Norberto Odebrecht) com a mesma proporção de capital, de $95 \%$ e de 5\%, respectivamente. $\mathrm{CEF}$, Embassa e consórcio vencedor acordaram a forma de operacionalização dos recursos destinados a compor o fundo garantidor (recebíveis da Embasa, formado por contas de água e esgoto previamente selecionadas de clientes que moram em uma área nobre da capital com a intenção de evitar a falta de pagamentos ou inadimplência para assegurar o pagamento da contraprestação). Conforme apontado por outro entrevistado.

A conta é constituída por créditos totalizando um valor maior que a contraprestação transferida à Foz do Brasil. Como um exemplo, em determinado mês o saldo da conta pode somar R\$ 1,5 milhão, no entanto o contrato estabelece o pagamento mensal de $\mathrm{R} \$ 1$ milhão, logo o excedente volta para o Estado. Esse valor maior funciona como um percentual de segurança para o recebimento pela concessionária (Coordenador de Sustentação ao Negócio da CEF).

As evidências demonstram que o processo de PPP é incipiente uma vez que divergências de opiniões sobre a dinâmica das PPP ainda persistem. Por exemplo, a lógica de financiamento e o modelo de negócio de PPP ainda não estão claros a alguns stakeholders, como órgãos de controle, conforme pode ser apreendido do relato de um dos entrevistados.

Uma coisa é o valor presente num fluxo de desembolso que o Estado vai fazer, e outra coisa é o valor do investimento ao se comprar um serviço. Era uma pergunta muito simples que eles faziam: como é que o valor presente no fluxo de desembolso do Estado é maior do que o valor da obra? (Secretário de Fazenda do Estado da Bahia). 
De toda a sorte, as próprias interações repetidas entre diferentes stakeholders podem contribuir para o próprio desenvolvimento da modalidade no país.

\section{Stakeholders controladores das Parcerias Público-Privadas}

Sobre a configuração do controle das PPP observa-se o ordenamento de maior complexidade, tendo em vista sua composição com um número maior de stakeholders, não raro com interesses concorrentes aos demais. Naturalmente, o governo do estado, concessionários e verificadores independentes têm graus elevados de controle, sobretudo nas fases de execução contratual. No entanto, nossas análises demonstram que determinados atores (stakeholders controladores) apresentam influência horizontal, ou seja, impactando diversos projetos, notadamente o Ministério Público (estadual e federal), Tribunal de Contas do Estado da Bahia (TCE-BA) e Procuradoria-Geral do Estado (PGE), que têm destacada função no controle do processo. Com efeito, o secretário responsável pela PPP da Fonte Nova revelou em entrevista que o encaminhamento do processo licitatório e a assinatura do contrato dependeram de aval positivo da PGE, o que, além de indicar a legalidade do empreendimento, conferiu, segundo ele, legitimidade ao processo das PPP como um todo.

O papel de controle desses stakeholders por vezes se contrapõe aos demais órgãos pertencentes à estrutura estatal, frequentemente explicitando tensões e incertezas. Por exemplo, tais atores em geral questionam o conceito das referidas parcerias e resistem ao tratamento dos projetos de PPP como negócios que diferem do modelo de obras públicas até então monitoradas. Segundo um entrevistado do alto escalão do governo da Bahia, o monitoramento ainda difuso aumenta a exigência de esclarecimentos e, em consequência, o custo para o estado, que precisa responder às recomendações oficialmente emanadas dos órgãos de controle, muitas delas descoladas da realidade de uma PPP.

Deve-se registrar que o Ministério Público não participa da tomada de decisões do Conselho Gestor de PPP e só tem conhecimento dos projetos por meio do que é divulgado em audiência pública. A promotora entrevistada caracteriza o papel do Ministério Público do Estado da Bahia contrastando importantes diferenças na atuação do Ministério Público do Estado da Bahia e da PGE. Em sua fala, ela ensina que a PGE não questiona a conveniência e a oportunidade das decisões, sendo esses aspectos do interesse do MPE. Ressalta-se também que o Ministério pode atuar de oficio, ou seja, sem ninguém provocar, para indagar sobre quaisquer escolhas feitas no desenvolvimento dos empreendimentos. Tais depoimentos revelam que as divergências observadas entre distintos stakeholders contribuem para menor celeridade, geração de incertezas e aumento nos custos de transação associados às PPP observadas.

\section{Stakeholders financiadores das Parcerias Público-Privadas}

Por fim, os bancos e as agências de fomento são alinhados como financiadores dos projetos de PPP, com a função principal de aportar recursos nas obras licitadas, inclusive podendo atuar como estruturador e controlador dos repasses durante a construção e a gestão dos projetos. São os financiadores das parcerias no estado da Bahia: a Desenbahia, o Banco no Nordeste, o BNDES, o Banco do Brasil, a Caixa Econômica Federal e o Banco Santander.

O processo de financiamento origina-se da apresentação de uma carta consulta pelo cliente ao banco, que analisa a proposta e defere dentro das condições normativas e negociais possíveis. Com base nesse projeto estudado pelo banco, analisa-se a capacidade de pagamento do empreendimento, inclusive o fluxo de caixa, o custo do capital próprio e de terceiros. Essa análise pode fluir de forma paralela à fase de enquadramento, para garantir que a contraprestação, o elemento principal do fluxo de caixa, assegure a capacidade do pagamento das prestações do financiamento junto ao banco, para que não sejam formatadas apenas para vencer o certame, oferecendo a menor contraprestação do leilão. Em seguida ao processo de crédito, a peça restante para firmar a contratação do financiamento junto ao banco será a assinatura entre o poder concedente e o concessionário.

Além de financiadores, os stakeholders acima também apresentam outros papéis. Um deles é o de controladores indiretos dos empreendimentos, uma vez que podem inviabilizar e impor restrições às PPP em curso, sobretudo na fase pré-operacional. Por exemplo, na Arena Fonte Nova as obras de demolição e a reconstrução foram contratadas pelo BNB com a forma de preço global, porque o objeto do contrato, diferentemente de outros projetos, não tem as especificações dos itens que 
recebem o recurso de cada um dos outros entes financiadores (BNB, BNDES e Desenbahia). Além disso, nesse projeto o BNB Nordeste desempenhou outro papel de atuação na forma de assessor de financeiro do consórcio vencedor, no que diz respeito à captação de recursos. De igual sorte, conforme revelam as entrevistas, a Desenbahia, também imbuída da função de financiamento da Arena, disponibiliza-se a apoiar qualquer projeto de investimento na Bahia, resguardando as restrições a financiamento que os entes públicos têm. Diante disso a obra passa a ser uma condição para contratar a oferta do serviço financeiro, reforçada pelo desempenho financeiro e pela segurança jurídica para atrair e manter o interesse privado em empreendimentos relacionados aos bens públicos, o que indica que a complementaridade de papéis desempenhados pelos financiadores apresentam externalidades positivas para a organização em si e para o arranjo como um todo.

Evidências do aprendizado cumulativo proporcionado pelas PPP são visíveis. No caso da Desenbahia, pouco a pouco a agência de fomento refina sua participação na estruturação do funding para outros projetos. As experiências iniciadas com os projetos da Arena Fonte Nova e do Hospital do Subúrbio têm sido usadas no desafio de custear o projeto de maior vulto do estado, representado pela implementação da PPP do Metrô de Salvador-Lauro de Freitas. Igualmente à Desenbahia, o BNB expande sua atuação para a fase de enquadramento, assessorando a composição da equação de equilíbrio econômico-financeiro do projeto, o que só foi possível por meio de competências adquiridas pelas experiências prévias de projetos de PPP.

\section{CONSIDERAÇÕES FINAIS}

O exame de três iniciativas de PPP no estado da Bahia permitiu compreender quais são os papéis dos stakeholders na conformação de PPP e como a atuação desses atores influenciam sua implementação.

Observou-se que, por meio de PPP, stakeholders atuando isoladamente ou em conjunto podem formular projetos, atrair parceiros, viabilizar sua execução e influenciar na entrega e controle de bens públicos por meio de atores privados. Contudo, todas as ações contidas nas parcerias têm nuances particulares a essa modalidade de gestão associada, em torno dos padrões ainda indefinidos em vários processos que tecem as interfaces entre os participantes. Por esse motivo, os interesses comuns se agregam para a implantação dos projetos e os objetivos divergentes concorrem para os benefícios das decisões atuais e futuras.

A pesquisa também revela que, nas PPP na Bahia, os stakeholders assumem diversos papéis. De fato, alguns deles, como agentes financeiros, podem ser financiadores, controladores e estruturadores dos projetos em diferentes fases do ciclo de vida da PPP. Os resultados apontam que alguns stakeholders situados na esfera de controle, como o Ministério Público e o Tribunal de Contas, tendem a apresentar padrões de comportamento divergentes dos stakeholders demandadores e estruturadores, não raro levando à emersão dos custos de transação associados às PPP. Observa-se também que tais divergências são acentuadas nas fases de construção, financiamento, gestão e controle dos contratos. Tal fato pode se dar pelo fato de as instituições de controle não participarem ativamente das fases iniciais de enquadramento ou por resistências intrínsecas em relação às novas configurações de provisão de serviços públicos envolvendo atores privados.

O exame da atuação dos stakeholders no âmbito das PPP na Bahia permite inferir que se encontra em curso um processo de acumulação progressiva de competências por parte das partes interessadas envolvidas, sobretudo nas fases iniciais do ciclo de vida dos projetos, muito em razão das experiências obtidas com iniciativas bem e malsucedidas ao longo dos últimos anos.

Com efeito, os erros e os acertos vividos em certos projetos possibilitam a sedimentação de experiências e a disseminação de práticas para outros projetos além da unidade governamental em que a PPP é concebida. A fertilização cruzada entre os vários stakeholders envolvidos aparenta ser o mecanismo pelo qual saberes e práticas são compartilhados e apropriados pelas demais partes interessadas.

Evidentemente, o trabalho apresenta algumas limitações. A primeira delas ligada ao restrito número de observações usadas e as consequentes restrições no que toca à generalização dos achados. A segunda refere-se ao caráter recente das PPP não só na Bahia, como também no Brasil, o que impede a observação de resultados concretos dessas experiências em uma perspectiva longitudinal mais ampla e, logo, limita a observação de como os diversos stakeholders se comportam em cenários em que os resultados esperados são atingidos e, sobretudo, quando não são observados. No entanto, acredita-se que os procedimentos adotados neste trabalho contornam em parte as barreiras acima mencionadas, fazendo que os achados e as conclusões da pesquisa sejam válidos. 
Por fim, este trabalho apresenta algumas implicações para as teorias de stakeholders no âmbito do setor público. Primeiro, os achados da pesquisa fornecem nuances acerca dos múltiplos papéis desempenhados por alguns atores. Tal diversidade pode contribuir para o avanço das PPP quando os objetivos são convergentes, porém, na presença de divergências, fomentadas sobretudo por atores com poder de veto, como órgãos de controle, a atuação multifacetada pode fazer que os projetos não avancem na velocidade inicialmente esperada pelo ator governamental patrocinador da PPP. Além disso, os resultados também sugerem que as interações entre os diversos stakeholders, bem como a troca de experiências entre as partes envolvidas, representam um importante aprendizado para futuros projetos. A experiência acumulada por stakeholders relevantes parece ser igualmente importante para que os erros e os acertos do passado possam ser incorporados às iniciativas do presente, indicando uma ampla possibilidade de futuras pesquisas, mesclando o conhecimento existente nas teorias dos stakeholders no setor público com a incipiente literatura relacionada ao exame de recursos e capacidades em organizações governamentais e em arranjos público-privados. 


\section{REFERÊNCIAS}

ALEXANDER, I. A taxonomy of stakeholders: human roles in system development. International Journal of Technology and Human Interaction, v. 1, n. 1, p. 23-59, 2005.

ALVARENGA, J. E. Parcerias público-privadas: comentários à lei brasileira. M. A. Pontes, 2005.

ARAGÃO, A. S. As parcerias público-privadas - PPPs no direito positivo brasileiro. Revista de Direito Administrativo, n. 240, p. 105-146, 2005.

AVISON, D. E.; WOOD-HARPER, A. T. A further exploration into information systems development: the evolution of multiview. Information Technology and People, v. 11, n. 2, p. 124-139, 1998.

BARBOSA, M.; CABRAL, S.; SOUZA, E. R. L. Mitigação de riscos em PPP: o caso do emissário submarino de Salvador, na Bahia. Panorama das Contas Públicas, v. 1, p. 149-162, 2009.

BARZELAY, M.; CORTAZAR-VELARDE, J. C. Una guía práctica para la elaboración de estudios de caso sobre buenas prácticas en gerencia social. Washington, DC: Banco Interamericano de Desarrollo/ Instituto Interamericano para el Desarrollo Social, 2004.

BOESSO, G.; KUMAR, K. An investigation of stakeholder prioritization and engagement: who or what really counts. Journal of Accounting and Organizational Change, v. 5, p. 62-80, 2009.

BOWKER, G. C.; LEIGH STAR, S. Sorting things out, classification and its consequences. Cambridge, MA: MIT Press, 1999.

BRASIL. Lei n. 11.079, de 30 de dezembro de 2004. 2004. Disponível em: <https://www.planalto.gov.br/ccivil_03/_Ato2004-2006/2004/ Lei/L11079.htm>. Acesso em: 2 set. 2015.

BRITO, B. M. B.; SILVEIRA. A. H. P. Parceria público-privada: compreendendo o modelo brasileiro. Revista do Serviço Público, n. 1, p. 7-20, 2005.

BRYSON, J. M. Strategic planning for public and non-profit organization. San Francisco, CA: Jossey-Bass, 1995.

CABRAL, S. Além das grades: uma análise comparada das modalidades de gestão do sistema prisional. Tese (Doutorado em Administração) - Universidade Federal da Bahia, Salvador, 2006.

CABRAL, S.; LAZZARINI, S; G.; AZEVEDO, P. F. Private entrepreneurs in public services: a longitudinal examination of outsourcing and statization of prisons. Strategic Entrepreneurship Journal, v. 7, n. 1, p. 6-25, 2013.

CABRAL, S.; SILVA JR., A. F. A. A verdade sobre os custos dos estádios para a Copa. A Tarde, p. 3, 9 abr. 2014.

CLARKSON, M. B. H. A stakeholder framework for analyzing and evaluating corporate social performance. Academy of Management Review, n. 20, p. 92-117, 1995.

COSSALTER, Phillipe. Private Finance Iniciative. Revista de Direito Público Econômico, n. 6, p. 127-180, 2004.

DAAKE, D.; ANTHONY, W. P. Understanding stakeholder power and influence gaps in a health care organization: an empirical study. Health Care Management Review, v. 25 n. 3, p. 94-107, Summer 2000.
DONALDSON, T.; PRESTON, L. The stakeholder theory of the corporation: concepts, evidence and implications. Academy of Management Review, v. 20, p. 65-91, 1995.

EVAN, W.; FREEMAN, R. A stakeholder theory of the modern corporation: Kantian capitalism. In: BEAUCHAMP, T.; BOWIE, N. (Eds.). Ethical theory and business. Englewood Cliffs, CA: Prentice Hall, 1993. 97-106 p.

FERNANDES, A. S. A.; ARAÚJO, S. M. V. G. A criação de municípios e a formalização de regiões metropolitanas: os desafios da coordenação federativa. Urbe: Revista Brasileira de Gestão Urbana, v. 7 n. 3, p. 295-309, 2015.

FERNANDES, M. E. História de vida: dos desafios de sua utilização. Revista Hospitalidade, v. 7, n. 1, p. 15-31, 2010.

FISCHBACHER, M.; BEAUMONT, P. B. PFI, Public-private partnerships and the neglected importance of process: stakeholders and the employment dimension. Public Money and Management, $\mathrm{v}$. 23, n. 3, p. 171-176, 2003.

FORRER, J. et al. Public-private partnerships and the public accountability question. Public Administration Review, v. 70, n. 3, p. 475484, 2010.

FREEMAN, R. E. Strategic management: a stakeholder approach. Boston: Pitman, 1984.

FREEMAN, R. E. The stakeholder approach revisited. Zeitschrift für Wirtschafts- und Unternehmensethik, v. 5, n. 3, p. 228-241, 2004

GOMES, R. C.; LIDDLE, J.; GOMES, L. O. M. A five-sided model of stakeholder influence. Public Management Review, v. 12, n. 5, p. 701-724, 2010a.

GOMES, R. C.; LIDDLE, J.; GOMES, L. O. M. Cross-cultural analysis of stakeholder identification in municipal districts. Public Management Review, v. 12, n. 1, p. 53-75, 2010b.

HASNAS, J. The normative theories of business ethics: a guide for the perplexed. Business Ethics Quarterly, v. 8, n. 1, p. 19-42, 1998.

HILLMAN, A. J.; KEIM, G. D. Shareholder value, stakeholder management, and social issues: what's the bottom line? Strategic Management Journal, v. 22, p. 125-139, 2001.

JONES, T. M.; WICKS, A. C. Convergent stakeholder theory. Academy of Management Review, v. 24, p. 206-221, 1999.

MASON, R. O.; MITROFF, I. I. Challenging Strategic Planning Assumptions: Theory, Cases and Techniques. NY: Wiley, 1981.

MITCHELL, R. K.; ANGLE, B. R.; WOOD, D. J. Toward a theory of stakeholder identification and salience: defining the principle of who and what really counts. Academy of Management Review, v. 22, n. 4 , p. 853-886, 1997.

PASIN, J. A. B. Desafios das parcerias público-privadas (PPPs). Rev. Adm. Pública, v. 39, n. 5, p. 1031-1052, 2005. 
PATTON, M. Q. Qualitative research. Hoboken, Nova Jersey: Wiley, 2005.

PINHEIRO, J. M.; GIAMBIAGI, F. Lucratividade, dividendos e investimentos das empresas estatais: uma contribuição para o debate sobre a privatização no Brasil. Revista Brasileira de Economia, v. 51, n. 1, p. 93-131, 1997.

SAVAGE, G. T. et al. Governance of integrated delivery systems/networks: a stakeholder approach. Health Care Management Review, v. 22, n. 1, p. 7-20, 1997.

SAVAS, E. S. Privatization and public-private partnerships. New York: Seven Bridges Press, 2000.
SHARP, H.; GALAL, G. H.; FINKELSTEIN, A. Stakeholder identification in the requirements engineering process. 1999. Disponível em: <http://discovery.ucl.ac.uk/744/1/1.7_stake.pdf>. Acesso em: 19 nov. 2015.

STRAUSS, A.; CORBIN, J. Basics of qualitative research: grounded theory procedures and techniques. Newbury Park, CA: Sage, 1990.

TEIXEIRA, M. A. C.; CABRAL, S. Legados gerenciais são a dimensão esquecida da Copa. Valor Econômico, p. 2, 12 ago. 2014.

WINSTANLEY, D.; SORABJI, D.; DAWSON, S. When the pieces don't fit: a stakeholder power matrix to analyse public sector restructuring. Public Money \& Management, v. 15, n. 2, p. 19-26, 1995.

Sandro Cabral

Doutor em Administração (UFBA); Professor da Escola de Administração da UFBA. E-mail: scabral@ufba.br

Antonio Sérgio Araújo Fernandes

Doutor em Ciência Política pela Universidade de São Paulo (USP); Professor da Escola de Administração da UFBA. E-mail: antoniosaf@ufba.br

Daniel Barroso de Carvalho Ribeiro

Mestre em Administração Núcleo de Pós-Graduação em Administração da Universidade Federal da Bahia (NPGA-UFBA); Professor da Universidade Federal do Piauí (UFPI). E-mail: danielbarroso.adm@gmail.com 